\title{
Spatial and temporal genetic differentiation among the seed in a stand of Fagus sylvatica L.
}

\author{
H.-R. Gregorius, \\ J. Krauhausen and \\ G. Müller-Starck
}

\begin{abstract}
Abteilung für Forstgenetik und Forstpflanzenzüchtung, Georg-August Universität Göttingen, Büsgenweg 2, 3400 Göttingen, Fed. Rep. Germany.
\end{abstract}

In a beech population composed of three parts (demes), the genetic structure of the seed (after dispersal) of each deme was recorded in two successive years and at five protein loci, four of which were polymorphic. Spatial and temporal differentiation, as evidenced in allele frequencies, genic diversity and heterozygosity, was studied. While no differentiation was found for diversity, allele frequencies and heterozygosity showed significant spatial differentiation at the genically most diverse loci in both years. Temporal differentiation measured as genetic differences between the seed production of the two years was distinctly lower. The total seed production over both years showed a tendency of homogenising spatial genetic differences present in each single year. This observation can be explained by local differences in flowering of the trees from one year to the next combined with non-random dispersal of the seed, where, however, the reproducing parts of the stand were genetically similar in both years.

Comparisons with the results of related studies on ponderosa pine revealed remarkable similarities in the amounts of spatial subpopulation differentiation. Noticeable differences occur with respect to the individual deme levels of differentiation. Consequences for the interpretation of adaptive strategies of trees are briefly discussed.

The data on diversities and conditional heterozygosities suggest that there is a tendency for rare alleles to occur preferentially in homozygous form among the seed. The significance of this phenomenon for the maintenance of genetic polymorphisms is demonstrated in the light of recent population genetic selection theories.

\section{INTRODUCTION}

Although beech is widely distributed, in many areas (e.g., in parts of central and south-eastern Europe) being the dominant forest tree species, studies of enzyme polymorphisms are very recent and still rare as compared to studies of other tree species, such as pine or spruce. Kim (1979) identified two isozyme loci and studied viability selection at early stages for two provenances in two environments (Kim 1980). His results demonstrate adaptability of the two loci. Thiebaut et al. (1982) found that among the three isozyme loci considered, two showed allele frequency variation among 13 populations, which indicates an influence of climatic factors. A tendency of allelic diversity to increase in marginal populations is preliminarily postulated. Müller-Starck (1985a) studied genetic effects of environmental stress dominated by air pollution at 14 isozyme loci by comparison of sensitive and tolerant individuals in a stand. He concluded that the tolerant part of the population appears to be more hetero- zygous and genetically diverse than the sensitive part.

The present paper concentrates on problems of genetic differentiation within a beech population. The presence or absence of genetic differentiation within populations is generally accepted to provide important information on adaptive systems characteristic of the species under consideration (Stern and Roche, 1974, chapter on adaptive strategies; Hamrick and Schnabel, 1985). This particularly applies to the concept that locally differential adaptation in combination with gene flow is an effective mechanism for the maintenance of genetic polymorphisms (Emlen, 1973, chapter 4 on selection in heterogeneous environments; Namkoong and Gregorius, 1985) and thus for the maintenance of adaptability (Gregorius et al., 1986).

Most plants are sessile organisms and the single individuals are, therefore, forced to adapt to local environmental conditions, which may be extremely variable across their habitats. Thus, local genetic differentiation will, in most cases, be the rule. Gene 
flow is mediated by pollen and seed migration, so that possibly existing tendencies for spatial homogenisation of genetic structures are likely to be most evident among the seed after dispersal. However, beech is known to show considerable variation in flowering intensity in both space and time (Rysavy, 1983), and the dispersal area of the heavy beech nuts is comparatively limited. Hence, spatial genetic differentiation after seed dispersal cannot a priori be considered as negligible. On the other hand, since different individuals may flower in different years, spatial differentiation may not accumulate over time. Even in the more comprehensively studied coniferous tree species, little seems as yet to be known about the interplay between spatial and temporal effects of pollen and seed dispersal on population differentiation (for an exception see Müller-Starck, 1985b, who investigated reproductive success of Scots pine genotypes in different years and spatial environments). The present study is based on frequency data for five isozyme loci obtained in a naturally substructured stand of beech for the seed production of two successive years. The results are thus suitable for providing some answers to the abovementioned problems of spatial and temporal differentiation.

\section{MATERIAL AND GENETIC TECHNIQUES}

\section{Stand and site}

The pure beech stand (Fagus sylvatica L.) studied is situated in southeastern Lower Saxony (FRG), state forest district of Bovenden, compartment 153, on a southeast facing slope in the Göttingen forest. The evaluation is $250-300 \mathrm{~m}$. The stand originates predominantly from natural regeneration, and the approximate ages of the adult trees range between 120 and 130 years. The soil has developed from a shell limestone formation, and is meso- to eutrophic (upper part of the slope) or eutrophic (lower part of the slope). Precipitation is $630 \mathrm{~mm}$ (50 per cent in the foliar period) without extended drought periods in summer.

The stand is divided into three parts by two forest roads running parallel to the slope. Sizes and population densities of the three parts are: per ha.

I. Lower part: 1.5 ha and about 200 trees

II. Middle part: $1 \cdot 1$ ha and about 150 trees per ha.

III. Upper part: $3 \cdot 0$ ha and about 100 trees per ha.

\section{Material}

Nuts were collected representatively (with respect to density) on the ground of the stand in the early winters of 1982 and 1983 . The density of nuts was 58 seeds $/ \mathrm{m}^{2}$ ( 44 per cent empty) in 1982 and 125 seeds $/ \mathrm{m}^{2}$ ( 38 per cent empty) in 1983 . According to the terminology of Kalbhenn (1963) the seed production of 1982 would be classified as "Sprengmast" (50-100 seeds $/ \mathrm{m}^{2}$; in English possibly "sporadic crop"), and 1983 would be a "Halbmast" (100-150 seeds $/ \mathrm{m}^{2}$; "half crop").

The nuts were stored at $0^{\circ}$ to $5^{\circ} \mathrm{C}$ in dry peat until they were analysed.

\section{Genotyping}

Multilocus genotypes were identified at five loci for the enzyme systems leucine aminopeptidase (LAP, EC 3.4.11.1), malate dehydrogenase (MDH, EC 1.1.1.37) and 6-phosphogluconate dehydrogenase (6-PGDH, EC 1.1.1.44).

The peeled nuts (embryos) were homogenised in a $0.08 \mathrm{M}$ tris $-1.00 \mathrm{M}$ HCL buffer, $p H 7 \cdot 3$, according to Kim (1980). The enzymes were separated by means of horizontal starch zone electrophoresis (for the buffer system consult MüllerStarck, 1985a). Genetic analysis was performed by studying the offspring from controlled crossings at the seed stage (Müller-Starck, in preparation).

Genotypic frequencies among the seed production were determined separately for the years 1982 and 1983, as well as for each of the three parts (upper, middle, lower) of the stand. In each of these six samples 160 acorns were analysed.

Most of the computations were performed with the help of the GSED-programme developed by E. Gillet (unpublished).

\section{RESULTS}

Among the five enzyme zones investigated, only MDH-A showed no variation. The single locus genotypic and allelic frequencies for the other four polymorphic zones are summarised in table 1 . Multilocus frequencies are not given, since pairwise tests for linkage disequilibrium revealed no significance.

The frequencies within the total seed production of each year were calculated by taking the weighted average over the three parts of the stand. The weights were computed from data available for the sizes of the three parts of the stand, seed density on the ground within each of these parts (1983), and observations of single tree fructification 
Table 1 Observed allelic and genotypic frequencies

\begin{tabular}{|c|c|c|c|c|c|c|c|}
\hline & & Lower & $\begin{array}{r}1982 \\
\text { Deme } \\
\text { Middle }\end{array}$ & Upper & Lower & $\begin{array}{c}1983 \\
\text { Deme } \\
\text { Middle }\end{array}$ & Upper \\
\hline LAP-A & $\begin{array}{l}A_{1} \\
A_{2} \\
A_{3} \\
A_{4} \\
A_{1} A_{2} \\
A_{1} A_{3} \\
A_{1} A_{4} \\
A_{2} A_{2} \\
A_{2} A_{3} \\
A_{2} A_{4} \\
A_{3} A_{3} \\
A_{3} A_{4} \\
A_{4} A_{4}\end{array}$ & $\begin{array}{r}1 \\
37 \\
135 \\
147 \\
0 \\
1 \\
0 \\
5 \\
13 \\
14 \\
46 \\
29 \\
52\end{array}$ & $\begin{array}{r}1 \\
42 \\
131 \\
146 \\
0 \\
1 \\
0 \\
8 \\
12 \\
14 \\
39 \\
40 \\
46\end{array}$ & $\begin{array}{r}0 \\
63 \\
147 \\
110 \\
0 \\
0 \\
0 \\
6 \\
28 \\
23 \\
47 \\
25 \\
31\end{array}$ & $\begin{array}{r}2 \\
51 \\
129 \\
138 \\
0 \\
0 \\
2 \\
8 \\
21 \\
14 \\
40 \\
28 \\
47\end{array}$ & $\begin{array}{r}1 \\
87 \\
100 \\
132 \\
0 \\
1 \\
0 \\
11 \\
27 \\
38 \\
20 \\
32 \\
31\end{array}$ & $\begin{array}{r}3 \\
53 \\
141 \\
123 \\
1 \\
1 \\
1 \\
6 \\
22 \\
18 \\
44 \\
30 \\
37\end{array}$ \\
\hline LAP-B & $\begin{array}{l}B_{2} \\
B_{3} \\
B_{4} \\
B_{2} B_{2} \\
B_{2} B_{3} \\
B_{2} B_{4} \\
B_{3} B_{3} \\
B_{3} B_{4} \\
B_{4} B_{4}\end{array}$ & $\begin{array}{r}245 \\
11 \\
64 \\
103 \\
0 \\
39 \\
5 \\
1 \\
12\end{array}$ & $\begin{array}{r}255 \\
12 \\
53 \\
111 \\
2 \\
31 \\
5 \\
0 \\
11\end{array}$ & $\begin{array}{r}270 \\
5 \\
45 \\
121 \\
0 \\
28 \\
2 \\
1 \\
8\end{array}$ & $\begin{array}{r}263 \\
9 \\
48 \\
113 \\
3 \\
34 \\
3 \\
0 \\
7\end{array}$ & $\begin{array}{r}262 \\
6 \\
52 \\
110 \\
0 \\
42 \\
3 \\
0 \\
5\end{array}$ & $\begin{array}{r}255 \\
15 \\
50 \\
116 \\
1 \\
22 \\
7 \\
0 \\
14\end{array}$ \\
\hline MDH-B & $\begin{array}{l}B_{2} \\
B_{3} \\
B_{4} \\
B_{5} \\
B_{6} \\
B_{2} B_{2} \\
B_{2} B_{5} \\
B_{3} B_{3} \\
B_{3} B_{5} \\
B_{4} B_{4} \\
B_{4} B_{5} \\
B_{5} B_{5} \\
B_{6} B_{6}\end{array}$ & $\begin{array}{r}4 \\
16 \\
42 \\
254 \\
4 \\
1 \\
2 \\
7 \\
2 \\
13 \\
16 \\
117 \\
2\end{array}$ & $\begin{array}{r}1 \\
13 \\
20 \\
282 \\
4 \\
0 \\
1 \\
4 \\
5 \\
7 \\
6 \\
135 \\
2\end{array}$ & $\begin{array}{r}0 \\
19 \\
32 \\
265 \\
4 \\
0 \\
0 \\
7 \\
5 \\
12 \\
8 \\
126 \\
2\end{array}$ & $\begin{array}{r}2 \\
8 \\
38 \\
268 \\
4 \\
1 \\
0 \\
3 \\
2 \\
14 \\
10 \\
128 \\
2\end{array}$ & $\begin{array}{r}2 \\
5 \\
26 \\
279 \\
8 \\
1 \\
0 \\
1 \\
3 \\
5 \\
16 \\
130 \\
4\end{array}$ & $\begin{array}{r}7 \\
10 \\
25 \\
270 \\
8 \\
3 \\
1 \\
4 \\
2 \\
6 \\
13 \\
127 \\
4\end{array}$ \\
\hline 6-PDGH-A & $\begin{array}{l}A_{2} \\
A_{3} \\
A_{2} A_{2} \\
A_{2} A_{3} \\
A_{3} A_{3}\end{array}$ & $\begin{array}{r}290 \\
30 \\
132 \\
26 \\
2\end{array}$ & $\begin{array}{r}295 \\
25 \\
135 \\
25 \\
0\end{array}$ & $\begin{array}{r}281 \\
39 \\
125 \\
31 \\
4\end{array}$ & $\begin{array}{r}294 \\
26 \\
138 \\
18 \\
4\end{array}$ & $\begin{array}{r}299 \\
21 \\
140 \\
19 \\
1\end{array}$ & $\begin{array}{r}293 \\
27 \\
133 \\
27 \\
0\end{array}$ \\
\hline
\end{tabular}

(1982). The weights are given in table 2 . The contribution of each year to the total seed production over both years is 31.6 per cent for 1982 and 68.4 per cent for 1983.

\section{LOCAL AND TEMPORAL DIFFERENCES IN GENETIC COMPOSITION}

In this section we shall analyse differences in gene frequencies among the three demes (upper, middle, lower) in each year and over both years. This will be done separately for each of the four polymorphic loci. Our aim is to answer the follow- ing four questions:

(a) Does a single stand contribute differently to the offspring of the two years?

(b) Are there genetic differences between the demes within each year, and are these differences consistent over the loci?

(c) Are the patterns of deme differentiation consistent over the years?

(d) Considering the total seed production of each deme, is there a tendency towards spatial homogenisation of genetic structures over the years?

The appropriate methods for answering these questions consist in the measurement of genetic 
distances and levels of differentiation. The latter is usually done by computing $F_{S T}$-values. However, since the interpretation of $F_{S T}$ as a measure of subpopulation differentiation is problematical (Wright, 1978, p. 84), we shall base our analysis on a measure which was recently proposed by Gregorius and Roberds (1986). This measure, $\delta$, is specified by the weighted average of the genetic distances of the demes from their population complements (i.e., the lumped remainder). The weights are given by the deme sizes, and the genetic distance between two populations $p$ and $q$ is

$$
d_{0}(p, q)=0 \cdot 5 \cdot \Sigma_{i}\left|p_{i}-q_{i}\right|,
$$

where $p_{i}$ and $q_{i}$ are the relative frequencies of the genetic types (here alleles) in the two populations. $d_{0}$ is the proportion of genetic elements (individual alleles) by which the two populations effectively differ, and thus $\delta$ is the proportion among all genetic elements in the population by which the demes effectively differ from their complements. The pattern of differentiation is described by the list of genetic distances of the demes from their respective complements (levels of single deme differentiation). The results are summarised in table 2.

The above questions can now be answered as follows:

(a) The genetic distances between the seed production of the two years $\left(d_{0}, 1982-83\right)$ are rather low, with a maximum of about 5 per cent allele differences at the locus MDH-B. Thus, even though the seed production in 1982 was less than half of that in 1983, and different trees contributed to the offspring in both years, essentially the same genes were successful in the same proportions at all loci studied. Consequently, it is likely that at these loci the representation of genes was largely the same among the reproducing parts of the stand in both years, and that within these parts the fertilities of each genotype were also about the same in both years.

(b) $F_{S T}$-values, being consistently below 1 per cent, suggest the almost complete absence of genic subpopulation differentiation at all loci and in both years. $\delta$-values are, on the average, about ten times larger, but still reveal little differentiation with one exception. In both years locus LAP-A shows a level of subpopulation differentiation which is about double that of the other loci. At this locus the demes effectively differ from their complements in 10.7 per cent and 8.5 per cent of the alleles in 1982 and 1983, respectively. The highest single deme levels of differentiation are 11.8 per cent for the upper deme in 1982 and 12.5 per cent for the middle deme in 1983. These levels of differentiation and, in addition, those of the lower deme in 1982 at the LAP-A locus, and the lower and upper deme in 1982 at the LAP-B locus are statistically significant (G-test, 5 per cent level of significance). 6-PDGH-A appears to be the least differentiated locus in both years. However, the $\delta$-values of MDH-B and LAP-B are also rather small, so that this statement is not particularly relevant.

Table 2 Subpopulation differentiation (\%)

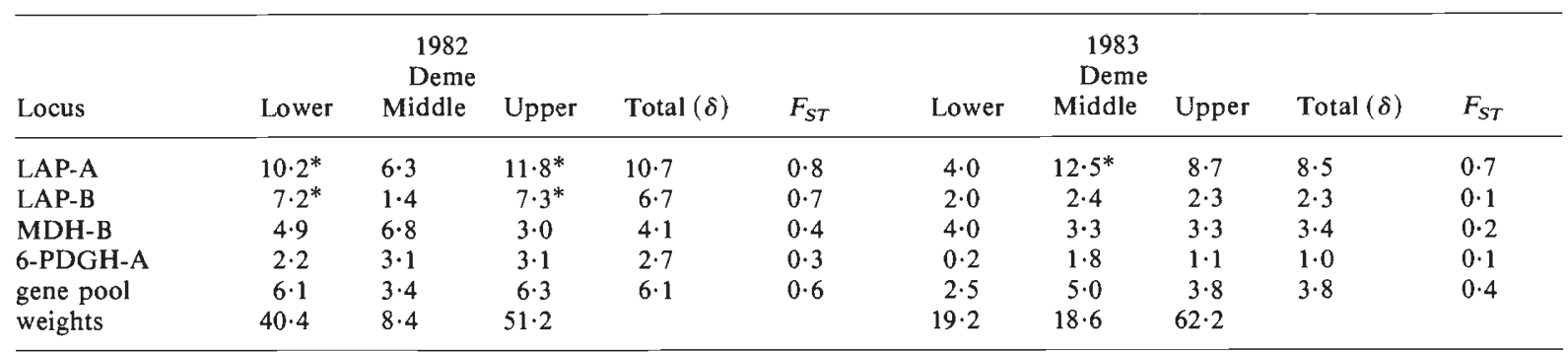

\begin{tabular}{lcccccc}
\hline \multicolumn{9}{c}{$\begin{array}{c}1982+1983 \\
\text { Deme }\end{array}$} & \multicolumn{3}{c}{ 1982-1983 } \\
Locus & Lower & Middle & Upper & Total $(\delta)$ & $F_{S T}$ & $d_{0}$ \\
\hline LAP-A & $6 \cdot 2$ & $11 \cdot 0^{*}$ & $6 \cdot 8$ & $7 \cdot 3$ & $0 \cdot 6$ & $3 \cdot 2$ \\
LAP-B & $2 \cdot 1$ & $1 \cdot 4$ & $1 \cdot 9$ & $1 \cdot 8$ & $0 \cdot 1$ & $1 \cdot 3$ \\
MDH-B & $4 \cdot 4$ & $4 \cdot 5$ & $2 \cdot 3$ & $3 \cdot 2$ & $0 \cdot 3$ & $5 \cdot 2$ \\
6-PDGH-A & $0 \cdot 2$ & $2 \cdot 5$ & $1 \cdot 5$ & $1 \cdot 3$ & $0 \cdot 1$ & $2 \cdot 7$ \\
gene pool & $3 \cdot 2$ & $4 \cdot 8$ & $3 \cdot 1$ & $3 \cdot 4$ & $0 \cdot 4$ & $3 \cdot 1$ \\
weights & $25 \cdot 9$ & $15 \cdot 4$ & $58 \cdot 7$ & & & \\
\hline
\end{tabular}

\footnotetext{
* = statistically significant single deme levels of differentiation (G-test, 5 per cent level of significance)
} 
Moreover, the low levels of differentiation at these loci do not allow for reliable inferences on consistency in the patterns of single deme levels of differentiation over the loci.

Since the $\delta$-values at the LAP-A locus are considerably larger for both years $(10 \cdot 7$ per cent, $8 \cdot 5$ per cent) and are more than 2.5 times the genetic distance between the total seed production of the two years $\left(d_{0}=3 \cdot 2\right.$ per cent $)$, it seems safe to conclude that, with respect to the present subpopulation structure and for this locus, the genic differentiation within the years (spatial differentiation) is greater than that between the years (temporal differentiation).

(c) The pattern of differentiation (i.e., the levels of the single deme differentiation) is not consistent over the years. At the LAP-A locus, the upper deme is the most $(11.8$ per cent $)$ and the middle deme the least strongly $(6.3$ per cent) differentiated in 1982; in 1983 the middle deme is the most $(12.5$ per cent $)$ and the lower deme the least (4 per cent) strongly differentiated. In different order, the same holds for the remaining loci, although at much lower levels of differentiation and thus with less significance. Hence, at least for the LAP-A locus, gene dispersal via pollen and seed has not occurred at random in the stand, and it is likely that in the same deme the genotypic frequencies among the reproductive trees differed between the years. Nevertheless, as was previously noted, the genotypic frequencies across all demes are likely to differ little between the reproducing parts of both years. This supports the frequent observation in beech that different trees flower in different years, which is interpreted as a consequence of differential allocation of resources to vegetative and generative functions. In this sense the present results may be explained by locally occurring genetic differences in resource allocation which, however, average out across the demes.

(d) Bulking for each deme the seed of both years $(1982+1983)$ reveals a clear (consistent over the loci) though slight tendency towards lowering spatial differentiation. This accords with the above findings and suggests that spatial genetic differentiation in the seed production within years does not accumulate over the years but rather declines.

\section{DIVERSITY AND HETEROZYGOSITY}

Following Crow and Kimura (1970, p. 323f), we shall measure the allelic diversity at a gene locus by the "effective number of alleles". In a more general context, Routledge (1979) and Gregorius (1978) independently concluded that, among the wealth of diversity measures in use, this effective number deserves priority on both conceptual and intuitive grounds. It is given by

$$
v=\left(\Sigma_{i} p_{i}^{2}\right)^{-1},
$$

where the $p_{i}$ 's are the relative allele frequencies. The generalisation to multiple loci, i.e., the gene pool diversity, results from taking the harmonic mean of the single locus diversities (Gregorius, unpublished).

In general, heterozygosity (the proportion of heterozygotes) is conditional on the allele frequencies, i.e., for different allele frequencies it may not be possible to have the same level of heterozygosity. For example, in a population with two equally frequent alleles at a locus, all individuals may be heterozygous, while this is impossible if one allele is more frequent than the other. Hence a proper evaluation of the actual level of heterozygosity should be made relative to the maximum level obtainable for the underlying allele frequencies. For arbitrary numbers of alleles at a locus, this maximum is equal to 1 (all individuals may be heterozygous) if all frequencies are less than or equal to $0 \cdot 5$, and it is equal to $2(1-p)$ if the most frequent allele has frequency $p$ greater than 0.5 (Gregorius, 1978). The above requirement is met by what will be called "conditional heterozygosity", which results from division of the actual heterozygosity by its corresponding maximum value. The results on genic diversities and the three types of heterozygosity (actual, corresponding Hardy-Weinberg, and conditional) are summarised in tables 3 and 4, respectively.

The problem consists now in the assessment of genic diversity and heterozygosity as possible factors of differentiation. Since, as was just shown, genic diversity is to some extent correlated with actual heterozygosity via the gene frequencies, an independent assessment of both factors requires that the conditional heterozygosity be considered instead of the actual heterozygosity. The pertinent observations have to be measured against the levels of genic deme differentiation (differentiation pattern) analysed in the last section. The following questions immediately emerge:

(a) Is the genic diversity unevenly distributed among the demes within each year and for both years jointly, and is there an association with the corresponding patterns of genic deme differentiation?

(b) Are there differences in genic diversity between the years? 
Table 3 Genic diversity

\begin{tabular}{|c|c|c|c|c|c|c|c|c|c|}
\hline & \multicolumn{3}{|c|}{1982} & \multirow[b]{2}{*}{ Total } & \multicolumn{3}{|c|}{1983} & \multirow[b]{2}{*}{ Total } & \multirow[b]{2}{*}{$1982+1983$} \\
\hline & Lower & Middle & Upper & & Lower & Middle & Upper & & \\
\hline LAP-B & $1.59(3)$ & $1 \cdot 51(3)$ & $1 \cdot 37(3)$ & $1.45(3)$ & $1.43(3)$ & $1 \cdot 43(3)$ & $1 \cdot 63(3)$ & $1.48(3)$ & $1.48(3)$ \\
\hline MDH-B & $1 \cdot 54(5)$ & $1 \cdot 28(5)$ & $1.43(4)$ & $1 \cdot 42(5)$ & $1.40(5)$ & $1 \cdot 30(5)$ & $1 \cdot 39(5)$ & $1 \cdot 37(5)$ & $1.42(5)$ \\
\hline 6-PDHG-A & $1 \cdot 20(2)$ & $1 \cdot 17(2)$ & $1 \cdot 27(2)$ & $1 \cdot 23(2)$ & $1 \cdot 18(2)$ & $1 \cdot 14(2)$ & $1 \cdot 18(2)$ & $1 \cdot 17(2)$ & $1 \cdot 19(2)$ \\
\hline
\end{tabular}

The number of alleles at each locus is given in brackets.

Table 4 Heterozygosity (\%)

\begin{tabular}{|c|c|c|c|c|c|c|c|c|c|}
\hline & & \multicolumn{3}{|c|}{1982} & \multirow[b]{2}{*}{ Total } & \multicolumn{3}{|c|}{1983} & \multirow[b]{2}{*}{ Total } \\
\hline & & Lower & Middle & Upper & & Lower & Middle & Upper & \\
\hline LAP-A & $\begin{array}{l}\text { actual } \\
\mathrm{H} \cdot \mathrm{W} \\
\text { condi. }\end{array}$ & $\begin{array}{l}35 \cdot 6 \\
59 \cdot 8 \\
35 \cdot 6\end{array}$ & $\begin{array}{l}41 \cdot 9 \\
60 \cdot 7 \\
41 \cdot 9\end{array}$ & $\begin{array}{l}47 \cdot 5 \\
63 \cdot 2 \\
47 \cdot 5\end{array}$ & $\begin{array}{l}43 \cdot 2 \\
62 \cdot 3 \\
43 \cdot 2\end{array}$ & $\begin{array}{l}40 \cdot 6 \\
62 \cdot 6 \\
40 \cdot 6\end{array}$ & $\begin{array}{l}61 \cdot 3^{*} \\
65 \cdot 9 \\
61 \cdot 3\end{array}$ & $\begin{array}{l}45 \cdot 6 \\
63 \cdot 1 \\
45 \cdot 6\end{array}$ & $\begin{array}{l}47 \cdot 6 \\
64 \cdot 0 \\
47 \cdot 6\end{array}$ \\
\hline LAP-B & $\begin{array}{l}\text { actual } \\
\text { H-W } \\
\text { condi. }\end{array}$ & $\begin{array}{l}25 \cdot 0 \\
37 \cdot 3 \\
53 \cdot 3\end{array}$ & $\begin{array}{l}20 \cdot 6 \\
33 \cdot 6 \\
50 \cdot 7\end{array}$ & $\begin{array}{l}18 \cdot 1 \\
26 \cdot 8 \\
57 \cdot 8\end{array}$ & $\begin{array}{l}21 \cdot 1 \\
31 \cdot 1 \\
55 \cdot 0\end{array}$ & $\begin{array}{l}23 \cdot 1 \\
30 \cdot 1 \\
64 \cdot 9\end{array}$ & $\begin{array}{l}26 \cdot 2 \\
30 \cdot 3 \\
72 \cdot 2\end{array}$ & $\begin{array}{l}14 \cdot 4 \\
38 \cdot 8 \\
35 \cdot 5\end{array}$ & $\begin{array}{l}18 \cdot 3 \\
32 \cdot 5 \\
47 \cdot 2\end{array}$ \\
\hline MDH-B & $\begin{array}{l}\text { actual } \\
\mathrm{H} \cdot \mathrm{W} \\
\text { condi. }\end{array}$ & $\begin{array}{l}12 \cdot 5 \\
35 \cdot 0 \\
30 \cdot 1\end{array}$ & $\begin{array}{r}7 \cdot 5 \\
21 \cdot 9 \\
31 \cdot 5\end{array}$ & $\begin{array}{r}8 \cdot 1 \\
30 \cdot 0 \\
23 \cdot 5\end{array}$ & $\begin{array}{r}9.9 \\
29.8 \\
25 \cdot 7\end{array}$ & $\begin{array}{r}7 \cdot 5 \\
28 \cdot 4 \\
23 \cdot 1\end{array}$ & $\begin{array}{l}11 \cdot 9 \\
23 \cdot 2 \\
46 \cdot 5\end{array}$ & $\begin{array}{l}10 \cdot 0 \\
28 \cdot 0 \\
31 \cdot 9\end{array}$ & $\begin{array}{r}9 \cdot 9 \\
27 \cdot 2 \\
32 \cdot 9\end{array}$ \\
\hline 6-PDGH-A & $\begin{array}{l}\text { actual } \\
\mathrm{H}-\mathrm{W} \\
\text { condi. }\end{array}$ & $\begin{array}{l}16 \cdot 2^{*} \\
17 \cdot 0 \\
86 \cdot 2\end{array}$ & $\begin{array}{c}15 \cdot 6^{*} \\
14 \cdot 4 \\
100 \cdot 0\end{array}$ & $\begin{array}{l}19 \cdot 4^{*} \\
21 \cdot 4 \\
80 \cdot 0\end{array}$ & $\begin{array}{l}17 \cdot 8^{*} \\
19 \cdot 0 \\
83 \cdot 3\end{array}$ & $\begin{array}{l}11 \cdot 2^{*} \\
14 \cdot 9 \\
68 \cdot 7\end{array}$ & $\begin{array}{l}11 \cdot 9^{*} \\
12 \cdot 3 \\
90 \cdot 8\end{array}$ & $\begin{array}{c}16 \cdot 9^{*} \\
15 \cdot 4 \\
100 \cdot 0\end{array}$ & $\begin{array}{l}14 \cdot 9 * \\
14 \cdot 7 \\
93 \cdot 1\end{array}$ \\
\hline
\end{tabular}

$\mathrm{H}-\mathrm{W}=$ corresponding Hardy-Weinberg heterozygosity. condi. = conditional heterozygosity.

* = no significant deviations from $\mathrm{H}-\mathrm{W}$ at the 5 per cent (G-test).

(c) What are the answers when question (a) and (b) are applied to heterozygosity in place of diversity?

(d) It is generally thought that rare alleles are more likely to occur in a heterozygous than in a homozygous state. Can this suggestion be confirmed by comparing genic diversities with conditional heterozygosities for the present data?

(a) and (b) The answer to both questions is "no". There is almost no differentiation at any of the loci with respect to genic diversity, neither spatial nor temporal. The slight increase in diversity at the LAP-A locus from 1982 to 1983 may be explained by the fact that in the latter year more trees flowered and that, therefore, a greater proportion of the total genic variation present in the stand entered into the seed production. This may also explain why the diversity of the total seed production over both years $(1982+1983)$ ranges between the diversities for the single years.

The locus (LAP-A) with the highest level $\delta$ of subpopulation differentiation is also the most diverse. While this might not be very surprising, it is still worth noting that the locus with the largest number of alleles found (MDH-B) is second to the last in diversity ranking, and its diversity values are considerably smaller than those at the LAP-A locus. Hence, measuring allelic diversity or variation by the number of alleles at a locus, which is still very frequently done, would have led to confusing conclusions with respect to the association between diversity and amount of subpopulation differentiation.

(c) Pairwise comparisons between deme heterozygosities show statistically significant (Gtest, 5 per cent level) spatial differences at the LAP-A locus in both years and at the LAP-B locus in 1983. However, there is no clear association between genic single deme differentiation and heterozygosity, with the possible exception of the LAP-A locus in 1983. Here, heterozygosity increases consistently with the level of genic deme differentiation. In addition, at this locus and in this year, both the levels of differentiation and the 
heterozygosities show the most distinct variation among the demes. However, since this is the only such case, it would be too extreme to conclude that heterozygosity was a driving force of spatial genic subpopulation differentiation. On the contrary, the results suggest that spatial genetic differentiation is more likely to have occurred independently for gene frequencies and heterozygosity. The same applies to temporal genetic differentiation. However, the previous observation that, on the genic level, spatial differentiation is greater than temporal also applies to both actual and conditional heterozygosity. The spatial variation in heterozygosity is very large, reaching maximum differences of more than 20 per cent for the actual heterozygosity (between the middle and lower deme in 1983 at the LAP-A locus) and more than 30 per cent for the conditional heterozygosity (between the upper and lower deme in 1983 at the 6-PDGH-A locus).

(d) With the exception of the 6-PDGH-A locus and the LAP-A locus in the middle deme in 1983, actual heterozygosity ranges consistently and significantly below the corresponding HardyWeinberg heterozygosity. This deviation is particularly strong at the MDH-B locus, where in almost all cases the Hardy-Weinberg heterozygosity is about three times larger than the actual. Considering the fact that this locus shows the largest number of rare alleles (low diversity and large number of alleles), one may suspect that there is a strong tendency for these rare alleles to occur preferentially in the homozygous state. This is corroborated by the observation that at this locus the conditional heterozygosity is distinctly the lowest among all loci in all demes and years.

A high average rate of self-fertilisation alone cannot sufficiently explain this observation. It is also difficult to speculate on other concrete mechanisms of the reproductive system which might cause such an effect. However, considering this result more generally as a problem of the establishment of alleles and the maintenance of genetic polymorphisms, an interesting correspondence to recent population genetic theories can be obtained. These theories state that the chances for the establishment and maintenance of a rare allele are considerably increased if it preferentially occurs in the homozygous state among the zygotes (Gregorius, 1984a,b). Since conditional heterozygosity is particularly suited to bring out the effects of rare alleles, the results of the present data analysis seem to support the view that increased homozygosity for these rare alleles may explain their presence.

\section{CONCLUDING REMARKS}

Our results demonstrate that the evaluation of the amount of subpopulation differentiation should encompass measurements of diversity. It appears that only at loci with sufficiently large genetic diversity can we expect forces enhancing spatial or temporal differentiation to become effective. Although this seems obvious, it is nevertheless worth emphasising, since frequent reports of low levels of genetic subpopulation differentiation may not be evidence for the absence of differentiating forces but may rather be a consequence of low genetic diversity at the loci studied. In this concern, as we have shown, it is important to use appropriate measures of diversity which account for both the number of alleles found and their frequencies. For protein polymorphisms, there is indeed ample evidence that at most of the polymorphic gene loci within populations, one allele dominates the others distinctly in frequency (for a survey see e.g., Nei and Graur, 1984), thus causing low allelic diversity. Hence, reports on low levels of differentiation have to be regarded with caution if they provide no information about the underlying degree of genetic diversity (and there appear to be very few which do).

In the present study, only one (LAP-A) of the four loci meets the requirement of sufficient diversity. Since related studies on beech (or other deciduous trees) do not yet exist, we are forced to compare our results on subpopulation differentiation with those known for conifers in order to be able to assess the magnitudes of genetic differentiation found here. Among the available data, those obtained by Linhart et al. (1981) for a sexually mature population of ponderosa pine seem to be best suited for this purpose. The population is composed of six demes (family clusters), and the genetic structure was recorded for seven protein loci with allelic diversities ranging from $v=1.05$ to $v=2 \cdot 12$ (recalculated). The largest single locus level of subpopulation differentiation was $11 \cdot 3$ per cent (recalculated in terms of the $\delta$-measure by Gregorius and Roberds, 1986), and it was realised at the locus with the highest allelic diversity. Hence there is a remarkable similarity between these results and ours. Noticeable differences occur with respect to the single deme levels of differentiation, where in some demes and at some loci the pine population reaches values between 16 per cent and 21 per cent (recalculated by Gregorius and Roberds, 1986), while in our beech population the maximum value is 12.5 per cent. However, it has to be recalled that the data of Linhart et al. refer 
to mature trees, while ours refer to the seed stage. Thus, this difference may be explained by the plausible suggestion that viability selection responds more readily to local environmental variation than mating systems and dispersal mechanisms. Moreover, comparing spatial with demographic (age class) differentiation, Linhart et al. concluded that in their population, genetic differentiation in time is much less marked than in space. This also accords with the present findings, in which the genetic differences between the seed production of two successive years are less than those between the demes in each year. This might serve as tentative evidence for the possibility that adaptive strategies of trees are characterised by the interplay between locally differential selection for viability and fertility and moderate dispersal abilities. Population genetic selection theories predict that this strategy is very effective in maintaining genetic polymorphisms and thus adaptability (Namkoong and Gregorius, 1985).

The latter consideration is also related to the observation that, in all three demes and in both years, conditional heterozygosity declines markedly with an increasing number of rare alleles. This contradicts the expectation that rare alleles, particularly if they are recent mutants or immigrants via pollen flow, should predominantly occur as heterozygotes, and it poses the question why rarity should have such an effect on the genotypic structure. It is difficult to conceive of any plausible mechanisms of the reproductive system which would cause alleles to be preferentially represented in homozygotes simply because they are rare. On the other hand, greater homozygosity among rare alleles raises their chances to become established and be maintained in a population, as long as the forces which are responsible for this increased frequency do not lower the fitness (Gregorius, 1984a, b). Thus, taking our observations for granted, this theory helps to explain the presence of larger numbers of rare alleles than are likely to originate from mutation or migration. However, it appears that nothing is yet known about the agents which may give rise to this interesting phenomenon.

Acknowledgement The authors appreciate the helpful comments of an anonymous reviewer. This work was by a grant from the Deutsche Forschungsgemeinschaft.

\section{REFERENCES}

CROW, J. F. AND KIMURA, M. 1970. An Introduction to Population Genetics Theory. Harper \& Row, New York, Evanston, London.
EMLEN, J. M. 1973. Ecology: An Evolutionary Approach. Addison-Wesley Publishing Company.

GREGORIUS, H.-R. 1978. The concept of genetic diversity and its formal relationship to heterozygosity and genetic distance. Math. Biosci., 41, 253-271.

GREGORIUS, H.-R. 1984a. Selection with two alleles and complete dominance. Biological Journal of the Linnean Society, $23,157-165$.

GREGORIUS, H.-R. 1984b. Allele protectedness in frequency dependent biallelic selection models with separated generations. J. Theor. Biol., 111, 425-446.

GREGORIUS, H.-R., HATTEMER, H. H., BERGMANN, F. AND MÜLLER-STARCK, G. 1985. Umweltbelastung und Anpassungsfähigkeit von Baumpopulationen. Silvae Genetica, in press.

GREGORIUS, H.-R. AND ROBERDS, J. H. 1986. Measurement of genetical differentiation among subpopulations. Theoretical and Applied Genetics, 71, 826-834.

HAMRICK, J. L. AND SCHNABEL, A. 1985. Understanding the genetic structure of plant populations: Some old problems and a new approach. Gregorius, H.-R. (ed.) In Population Genetics in Forestry, Lecture Notes in Biomathematics 60, Springer-Verlag, 50-70.

KALBHENN, R. 1963. Untersuchung über die natürliche Verjüngung der Buche. Samenproduktion der Mast 1960, Überwinterung und Keimung der Bucheckern. Dissertation der Universität Göttingen.

KIM, Z.-S. 1979. Inheritance of leucine aminopeptidase and acid phosphatase isozymes in beech (Fagus sylvatica L.). Silvae Genetica 28, 68-71.

KIM, Z.-S. 1980. Veränderung der genetischen Struktur von Buchenpopulationen durch Viabilitätsselektion im Keimlingsstadium. Göttingen Research Notes in Forest Genetics, $3,1-84$.

LINHART, Y. B., MITTON, J. B., STURGEON, K. B. AND DAVIS, M. L. 1981. Genetic variation in space and time in a population of ponderosa pine. Heredity 46, 407-426.

MÜLLER-STARCK, G. 1985a. Genetic differences between "tolerant" and "sensitive" beeches (Fagus sylvatica L.) in an environmentally stressed adult forest stand. Silvae Genetica, in press.

MÜLLER-STARCK, G. 1985b. Reproductive success of genotypes of Pinus sylvestris L. in different environments. Gregorius, H.-R. (ed.) in Population Genetics in Forestry. Lecture Notes in Biomathematics, 60, Springer-Verlag, 118-133.

NAMKOONG, G. AND GREGORIUS, H.-R. 1985. Conditions for protected polymorphisms in subdivided plant populations. 2. Seed versus pollen migration. Amer. Nat. 125, 521-534.

NEI, M. AND GRAUR, D. 1984. Extent of protein polymorphism and the neutral mutation theory. Hecht, M. K., Wallace, B. and Prance, G. T. (eds.) In Evolutionary Biology. Vol. 17, Plenum Press, New York, London, 73-118.

ROUTLEDGE, R. D. 1979. Diversity indices: Which ones are admissible? J. theor. Biol., 76, 503-515.

RYSAVY, T. 1983. Beobachtungen einer Blüte in einem Buchenbestand und einige populationsgenetische Konsequenzen. Diplomarbeit an der Forstlichen Fakultät der Universität Göttingen.

STERN, K. AND ROCHE, L. 1974. Genetics of Forest Ecosystems. Springer-Verlag, Berlin, Heidelberg, New York.

THIEBAUT, B., LUMARET, R. AND VERNET, Ph. 1982. The bud enzymes of beech (Fagus sylvatica L.). Genetic distinction and analysis of polymorphisms in several French populations. Silvae Genetica, 31, 51-60.

WRIGHT, S. 1978. Evolution and the Genetics of Populations, Vol. 4, University of Chicago Press, Chicago. 